\title{
Assessment of Clinical Governance in Primary Health Care Services: A Case Study on Dakahlia Governorate, Egypt
}

\author{
Thoraya A. Abd El Fatah ${ }^{(1)}$, Nagafa A. Ali ${ }^{(1)}$, Emad M Elazazy ${ }^{(2)}$, Nabil L Dowidar ${ }^{(3)}$, \\ Heba M. Abd Elgalil ${ }^{(1)}$, Soso S. Mohamed ${ }^{(1)}$, \\ (1) Department of Community and Occupational Medicine, Faculty of Medicine for Girls, Al-Azhar University \\ (2) Cambridge regional UK, ${ }^{(3)}$ Medical Research Institute, Alexandria University \\ *Correspondence author: Soso S. Mohamed, Mobile: (+20) 01006197894, E-mail: sososhawky85@ gmail.com
}

\begin{abstract}
Background: universal health coverage and the health-related sustainable development goals can only be achieved with a stronger emphasis on Primary Health Care (PHC). In spite of the essential role of clinical governance (CG) in enhancing quality of services provided by PHC facilities, a scientific framework with precise criteria for evaluating them has not been developed so far in Egypt.
\end{abstract}

Objective: to assess the CG in PHC in Egypt considering PHC of Al-Dakahlia governorate as a case study and to clarify the barriers for implementing CG at PHC.

Subjects and Methods: a cross sectional study was conducted over a period of one year at 8 PHC facilities in selected two districts; Al-Sinbelawin and Aga in Al-Dakahlia governorate, Egypt. The assessment of CG indicators was through multi-level approaches from different perspectives of 327 PHC utilizers, 40 PHC providers, 10 PHC executive directors who were drawn from the selected districts. Thirteen experts in PHC and CG in Egypt were also participated.

Results: CG index for PHC facilities was scored higher percentage degree by PHC directors (91.0\%) than by PHC utilizers, providers and the experts $(70.0 \%, 59.6 \% \& 53.3 \%$ respectively). The CG indicators showed disparities between the participating groups. Experts reported several challenges for CG implementation as shortage of clear policies, lack of awareness about governance culture and lack of experience in this field.

Conclusion: the successful CG framework should be based on plan \& implement as a team and create better relationships between directors and all stakeholders.

Keywords: Clinical governance, Primary health care, Egypt.

\section{INTRODUCTION}

Clinical governance isn't new concept. It was introduced in the late-1990s in the United Kingdom following exposure to number of failures within the National Health Service (NHS) ${ }^{(\mathbf{1})}$.

It is widely accepted that clinical governance (CG) provides a unique and comprehensive strategy for bringing all local activities into a single coherent program for continuous quality improvement as a systematic model ${ }^{(2)}$. It encourages everyone in the organization to work for improving quality and safety of patient care ${ }^{(3)}$.

Primary health care (PHC) is considered as the cornerstone for universal health coverage (UHC) ${ }^{(4)}$. Also, the health-related sustainable development goals (SDGs) can only be achieved with a stronger emphasis on $\mathrm{PHC}^{(5)}$. However, there is a sharp decline in its usage in many developing countries. That may be attributed to failure of health system to respond to many problems as lack of access to essential drugs and lack of health care workers ${ }^{(6)}$. In addition to scarceness of strategies for implementation and its monitoring for accountability ${ }^{(7)}$. Renewing PHC and placing it at the center of efforts to improve health are critical to respond to rapidly changing world ${ }^{(5)}$.

Egypt has a population of 92.1 million and has approximately $5314 \mathrm{PHC}$ facilities with 14,973 general practitioners and 256 certified family physicians (FPs) and 80,000 beds nationwide, $61 \%$ of these facilities implemented as a family practice approach based on formal accreditation ${ }^{(\mathbf{8})}$. It witnessed several health gains during the past decades as $95 \%$ of the population has access to primary health care within $5 \mathrm{~km}^{(9)}$.

In Egypt, different means were considered to improve the quality and safety of care delivered within the primary care sector through implementation of Continuous Quality Improvement (CQI) and Quality Assurance (QA) initiatives ${ }^{(\mathbf{1 0})}$. Furthermore, Egypt has experienced a number of initiatives for health reform in the public sector from 1997 to-date. Building blocks of Health Sector Reform Program (HSRP) were as following: establishment of a new family healthcare model, separation of finance from provision of healthcare, decentralization, application of quality and accreditation, and coverage of new population groups with insurance scheme (11). Another initiative is the new universal health coverage law that received parliamentary approval in mid-December 2017 after years of discussion and planning ${ }^{(12)}$. Egypt has clearly set UHC as a priority objective for health sector development. Article 18 in 2014 constitution has paved the path for UHC through implementation of social health insurance (SHI). The MOHP "white paper" has confirmed that UHC is a strategic vision for health sector development and the health pillar in the SDGs. Strategy-Egypt 2030 has incorporated the objectives of 
UHC to the overall vision for Egypt's development for $2030^{(13)}$.

However, in Egypt, this concept is still in its infancy and it is too early to full development of all principles and needs more research to clarify the barriers impeding the implementation of CG. So, the assessment of clinical governance in PHC (family health) facilities at one of the largest governorates in Egypt and delta region will be a step forward as a case study to clarify all concepts and practices toward clinical governance.

\section{AIM OF THE STUDY}

It is to assess the concepts and practices of clinical governance in Primary Health Care in Egypt through Multi-level approaches from different perspectives of PHC utilizers, providers, directors and experts considering PHC of Al-Dakahlia governorate as a case study and to demonstrate the barriers for implementing CG as well as to address the needs in attempt to develop lines of a model suit for CG in PHC in Egypt.

\section{SUBJECTS AND METHODS \\ Study design:}

A cross sectional approach was adopted to carry out the current survey at 8 PHC (family health) facilities (4 of them were only accredited) in the selected two districts; Al-Sinbelawin and Aga in AlDakahlia governorate, Egypt by using multistage random sample technique. This study was conducted over a period of one year from November 2016 to November 2017.

\section{Sampling:}

The study included 327 PHC utilizers that were chosen using a systematic random sample technique. Sample size was estimated with $95 \%$ confidence level with expected rate of occurrence not over $30 \%$ or not less than $70 \%$ with a population sample 500,000 or more, the sample size for reliability of $\pm 5 \%$ was 322 from both districts ${ }^{(\mathbf{1 4})}$. Also, 40 PHC providers, 10 PHC executive directors who were on work during the study period from the two selected districts (Al-Sinbelawin and Aga) at Al-Dakahlia governorate equally were included in the study. In addition, 13 experts in PHC and clinical governance in Egypt who have more than 5years' experience in health policy, decision making, as governmental bodies in the central and peripheral levels were also participated their selection was through personal communication to nominated persons.

\section{Tools of the study:}

The participants were asked to fulfill the survey questionnaires, which were designed to achieve the research objectives.

\section{I- The questionnaire of health experts:}

Self-reported semi-structured questionnaire, each item was scored using a five-point Likert scale terms of agreement (strongly agree, agree, neutral, disagree and strongly agree).

II- The questionnaire of PHC providers and executive directors.

III- The questionnaire of family health services utilizers:

CG was assessed through participants' views, opinions and applications of its elements in PHC which include; efficiency, clinical effectiveness, evidencebased practice \& research, training, clinical audit, clinical risk management, equity, transparency, health information management, participation, responsiveness, accountability, role of law and combating corruption.

\section{Ethical consideration:}

The protocol of the study was approved by the Ethics Committee of Al-Azhar University, Faculty of Medicine for Girls. Also, the approval on the research from Ethical and Research Committee at MOHP was taken. The aim of the research was explained to the participants of the four groups; those who agreed to participate were included in the study.

\section{Statistical analysis:}

Data collected were reviewed, coded, and statistical analysis was done by using SPSS program version 17. Continuous data were described in terms of mean \pm standard deviation (SD), whereas categorical variables were described in number and percentage. Student's t-test was used for quantitative data. The level of significance was taken at $p$ value $\leq 0.05$ and the results were represented in tables and figures.

\section{RESULTS}

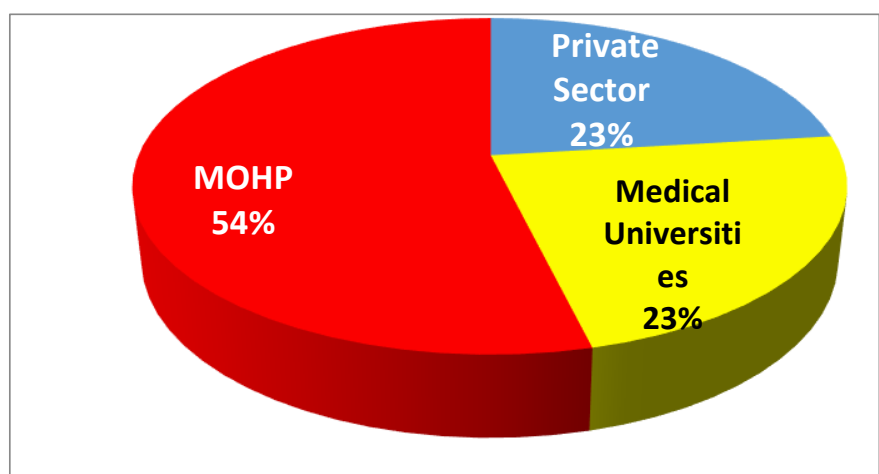

\section{Figure (1): Distribution of the interviewed PHC experts.}

Figure (1) showed that nearly half $(53.0 \%)$ of participating experts working in the MOHP while the rest $(46.2 \%)$ were equally chosen from the medical universities and private health sector. With years of experience in field health ranged from 8-40 years. 


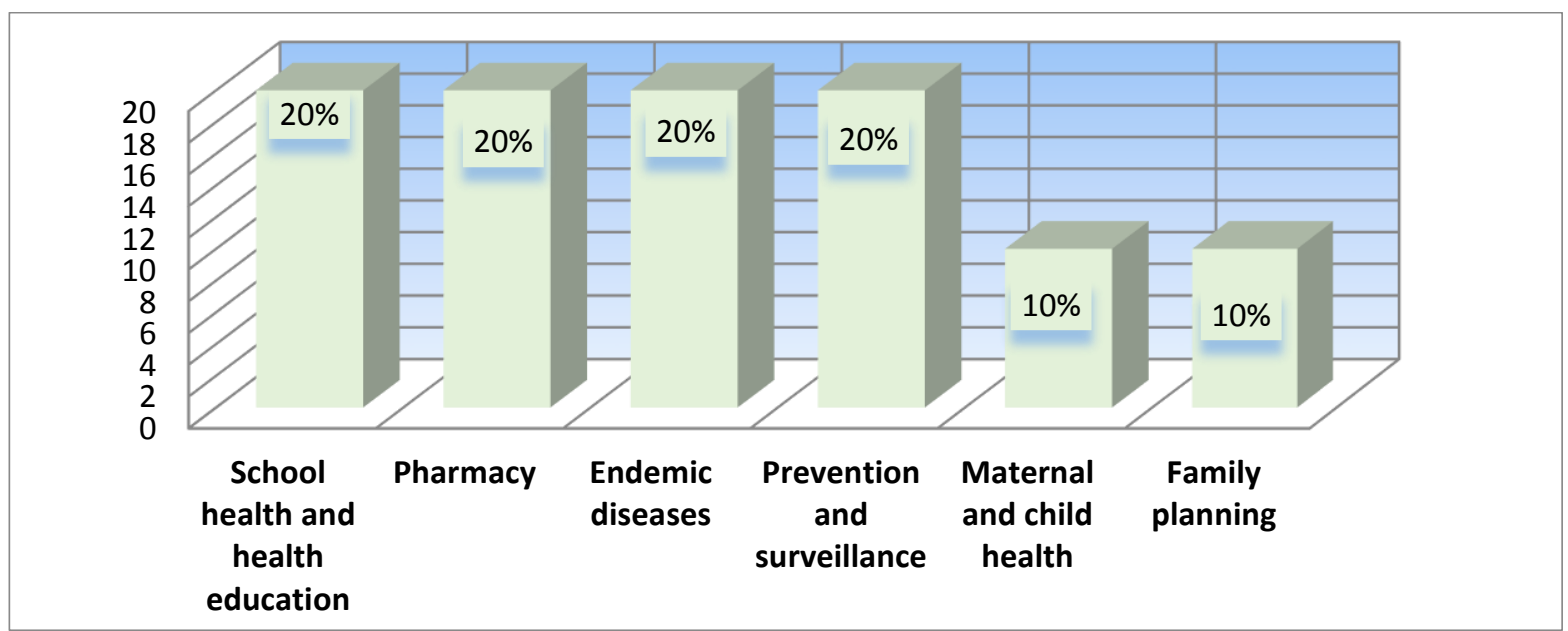

Figure (2): Distribution of the interviewed primary health care executive directors regarding departments

Figure (2) illustrated that the participated 10 directors were selected equally from the two health districts. They were chosen from different departments such as school health and health education; pharmacy, endemic diseases, prevention and surveillance (20.0\% for each) as well as maternal and child health and family planning (10.0\% for each).

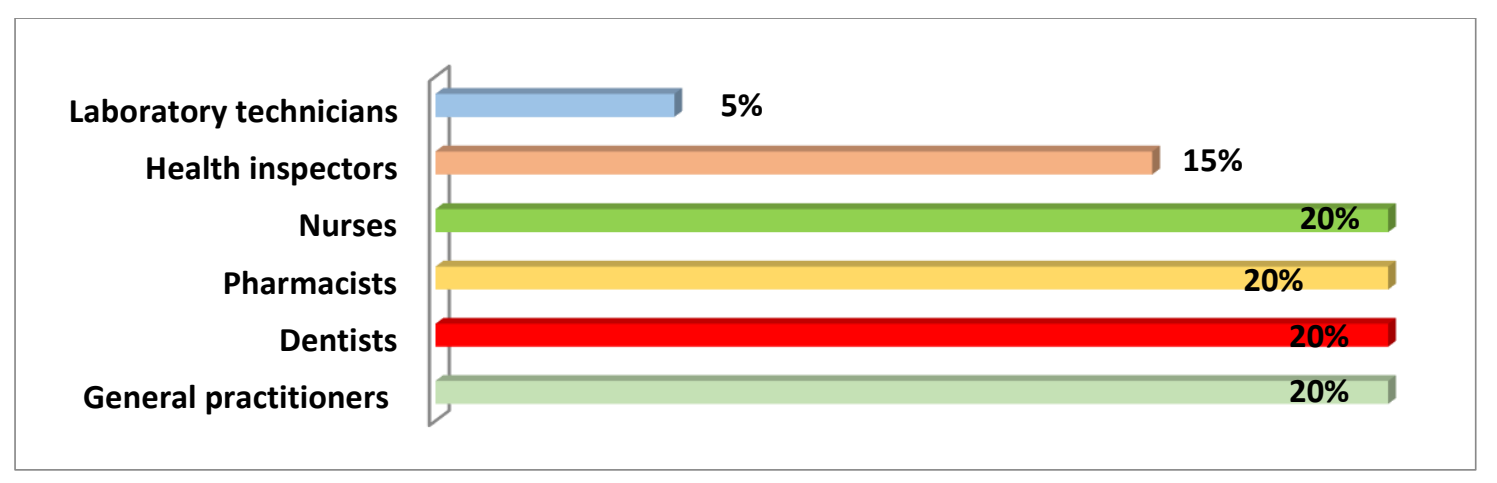

Figure (3): Distribution of the interviewed primary health care providers regarding their specialty

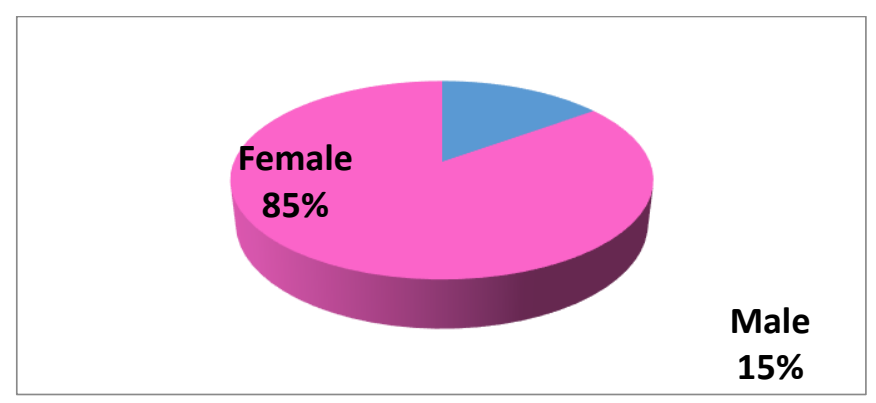

Figure (4): Distribution of the interviewed primary health care providers according to sex

Figures $(\mathbf{3 , 4})$ showed that most $(80 \%)$ of them were general practitioners, dentists, pharmacists and nurses $(20 \%$ for each) while the rest were health inspectors and laboratory technicians $(15.0 \% \& 5.0 \%)$ respectively and the majority $(85.0 \%)$ were females. 
ejhm.journals.ekb.eg

Table (1): General characteristics of the primary health care interviewed utilizers

\begin{tabular}{|c|c|c|c|c|}
\hline \multicolumn{3}{|r|}{ Interviewed PHC utilizers } & \multicolumn{2}{|c|}{$\begin{array}{c}\text { Total NO. }=3 \\
100 \%\end{array}$} \\
\hline \multicolumn{3}{|l|}{$\begin{array}{l}\text { Age: } \\
\text { Range (Years) } \\
\text { Mean } \pm \text { SD } \\
\end{array}$} & \multicolumn{2}{|c|}{$\begin{array}{l}18-67 \text { year } \\
34.3 \pm 11.5 \text { year }\end{array}$} \\
\hline \multirow{2}{*}{\multicolumn{2}{|c|}{$\begin{array}{l}\text { Sex: } \\
\text { Female } \\
\text { Male }\end{array}$}} & & NO. & $\%$ \\
\hline & & & $\begin{array}{c}230 \\
97\end{array}$ & $\begin{array}{l}70.3 \\
29.7\end{array}$ \\
\hline \multicolumn{3}{|c|}{ Distribution of utilizers according to health district and accreditation } & \multirow[b]{2}{*}{$\begin{array}{l}55 \\
56\end{array}$} & \multirow[b]{2}{*}{$\begin{array}{l}16.8 \\
17.1\end{array}$} \\
\hline \multirow[t]{2}{*}{ Aga } & Accredited & $\begin{array}{l}\text { Sangeed Family Health Center } \\
\text { Ekhtab family health center }\end{array}$ & & \\
\hline & Not accredited & $\begin{array}{l}\text { Al Bahao family health unit } \\
\text { Met Fadala family health unit }\end{array}$ & $\begin{array}{l}26 \\
27\end{array}$ & $\begin{array}{l}8.0 \\
8.2\end{array}$ \\
\hline \multirow[t]{2}{*}{ Al-Sinbillawin } & Accredited & $\begin{array}{l}\text { Tokh Al Aklam family health unit } \\
\text { Tanbool Al Kobra family health center }\end{array}$ & $\begin{array}{l}56 \\
55\end{array}$ & $\begin{array}{l}17.1 \\
16.8\end{array}$ \\
\hline & Not accredited & $\begin{array}{l}\text { Nob Taref family health unit } \\
\text { Met Ghorab family health unit }\end{array}$ & $\begin{array}{l}26 \\
26\end{array}$ & $\begin{array}{l}8.0 \\
8.0\end{array}$ \\
\hline
\end{tabular}

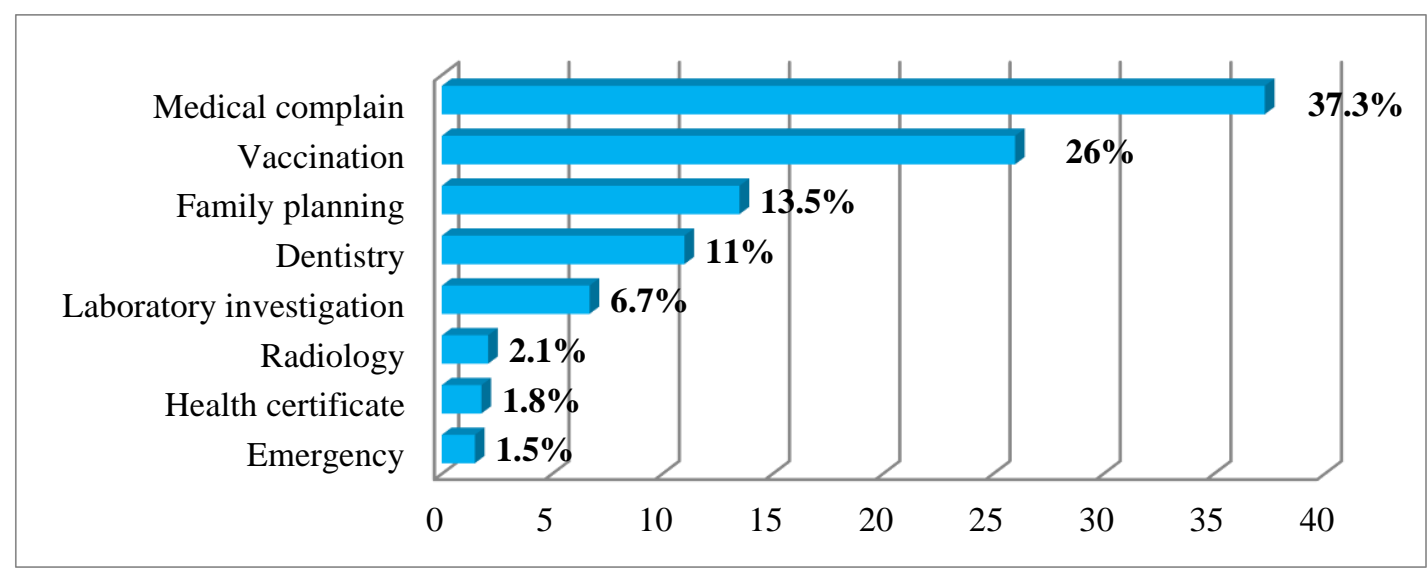

Figure (5): Cause of visit of primary health care utilizers to primary health care facility

Table (1) showed that utilizers' ages ranged from18-67 years with a mean of $34.3 \pm 11.5$ years, most $(70.3 \%)$ of them were females. It was found that nearly two thirds $(67.8 \%)$ of them recruited from accredited PHC facilities (Sangeed Family Health Center and Ekhtab family health center in Aga district and Tokh Al Aklam family health center and Tanbool Al Kobra family health unit in Al Sinbillawin district) and four (32.2\%) were not accredited (Al Bahao family health unit and Met Fadala family health unit in Aga district and Nob Taref family health unit and Met Ghorab family health unit in Al Sinbillawin district). 
Table (2): Comparison of clinical governance index among the studied groups

\begin{tabular}{|l|c|c|c|c||}
\hline \hline \multicolumn{1}{|c|}{ Studied group } & $\begin{array}{c}\text { Health care } \\
\text { providers } \\
\text { (Mean \%) }\end{array}$ & $\begin{array}{c}\text { Health } \\
\text { directors } \\
\text { (Mean \%) }\end{array}$ & $\begin{array}{c}\text { PHC } \\
\text { utilizers } \\
\text { (Mean \%) }\end{array}$ & $\begin{array}{c}\text { Experts } \\
\text { Mean \%) }\end{array}$ \\
\hline Efficiency & 62.7 & 91.8 & 85.0 & 58.3 \\
\hline Effectiveness & 57.5 & 89.3 & 94.6 & 53.8 \\
\hline Research and evidence-based practice & $\mathbf{1 5 . 5}$ & 94.0 & - & 61.5 \\
\hline Training of health team & 67.5 & 100 & - & 53.8 \\
\hline Clinical audit & 62.5 & 91.1 & - & 59.0 \\
\hline Clinical risk management & 93.3 & 100 & 99.5 & 68.4 \\
\hline Equity & 51.8 & 62.2 & 93.0 & - \\
\hline Transparency & $\mathbf{3 3 . 8}$ & 81.0 & 61.5 & $\mathbf{2 0 . 5}$ \\
\hline Health information management & 92.5 & 100 & - & 61.5 \\
\hline Participation & 55.8 & 96.7 & $\mathbf{0 . 2}$ & $\mathbf{3 6 . 5}$ \\
\hline Responsiveness & 69.6 & 100 & 50.5 & - \\
\hline Accountability & 65.3 & 95.8 & $\mathbf{1 3 . 4}$ & 59.0 \\
\hline Combating corruption & 66.8 & 72.5 & 54.6 & - \\
\hline Role of law & $\mathbf{4 0 . 2}$ & 100 & - & $\mathbf{4 8 . 7}$ \\
\hline Total mean percentage of clinical governance ind & $\mathbf{5 9 . 6}$ & $\mathbf{9 1 . 0}$ & $\mathbf{7 0 . 0}$ & $\mathbf{5 3 . 3}$ \\
\hline
\end{tabular}

Figure (5) showed that medical complain (37.3\%), vaccination (26.0\%), family planning (13.5\%) and dentistry $(11.0 \%)$ were the most common causesfor visiting the PHC facilities.

Table (2) showed that clinical governance index for PHC facilities was scored higher degree by PHC directors $(91.0 \%)$ than by PHC utilizers, providers and the experts $(70.0 \%, 59.6 \% \& 53.3 \%$ respectively). It was noticed that clinical risk management and health information management were the highest scored indicators among the studied groups. However, research and evidence-based practice (15.5\%), transparency (33.8\%) and role of law (40.2\%) were the lowest scored indicators among PHC providers. Also, participation $(0.2 \%)$ and accountability $(13.4 \%)$ were the lowest scored indicators among PHC utilizers. Among the experts, role of law (48.7\%), participation (36.5\%) and transparency $(20.5 \%)$ were the lowest scored indicators.

Table (3): Health experts' view about clinical governance implementation barriers

\begin{tabular}{|c|c|c|}
\hline \multirow[t]{2}{*}{ Studied group } & \multicolumn{2}{|c|}{ Total NO. $=13$} \\
\hline & $\begin{array}{c}\text { Yes } \\
\mathbf{N}(\%)\end{array}$ & $\begin{array}{c}\text { NO } \\
\mathbf{N}(\%)\end{array}$ \\
\hline Presence of barriers for implementing clinical governance aspects: & $11(84.6 \%)$ & $2(15.4 \%)$ \\
\hline $\begin{array}{l}\text { Barriers against implementing clinical governance aspects*: } \\
\text { Shortage of clear policies, laws and regulations for clinical governance } \\
\text { Lack activation of the policies due to political obstacles } \\
\text { Lack of a culture of governance and low awareness about clinical governance } \\
\text { Lack of experience to apply it } \\
\text { There is no real will to implement governance aspects } \\
\text { Inappropriate organizational structure of health system } \\
\text { Fragmentation of services provision between public and private sectors } \\
\text { Absence of participatory vision from all stakeholders } \\
\text { Inappropriate health care work environment } \\
\text { Weak supervision and monitoring mechanisms }\end{array}$ & $\begin{array}{l}3(2 \\
3(2 \\
3(2 \\
2(1 \\
2(1 \\
2(1 \\
2(1 \\
1(7 \\
1(7\end{array}$ & $\begin{array}{l}.1) \\
\text { 1) } \\
\text {.1) } \\
\text { 4) } \\
\text { 4) } \\
\text { 4) } \\
\text { 7) } \\
\text { 7) }\end{array}$ \\
\hline
\end{tabular}


*: The percentage exceeded $100 \%$ due to more than one answer by the experts

Table (3) demonstrated that the majority $(84.6 \%)$ of experts reported presence of barriers for implementing clinical governance aspects in the form of shortage of clear policies, laws and regulations for clinical governance, lack activation of the policies due to political obstacles and lack of a culture of governance and low awareness about clinical governance $(23.1 \%)$ for each. Followed by lack of experience to apply it, with no real will to implement its aspects, inappropriate organizational structure of health system and fragmentation of services provision between public and private sectors (15.4\%) for each. Finally they added absence of participatory vision from all stakeholders, inappropriate health care work environment with weak supervision and monitoring mechanisms (7.7\%) for each.

Table (4): Health experts' suggestions for improving primary health care quality

\begin{tabular}{|c|c|c|}
\hline \multirow[t]{2}{*}{ Studied group } & \multicolumn{2}{|c|}{ Total No. $=13$} \\
\hline & $\begin{array}{c}\text { Yes } \\
\mathbf{N}(\%)\end{array}$ & $\begin{array}{c}\text { No } \\
\mathbf{N}(\%)\end{array}$ \\
\hline $\begin{array}{l}\text { Suggestions for improving the quality** } \\
\text { Improving health budget } \\
\text { Continuous evaluation and improvement of PHC service quality } \\
\text { Develop a system for continuous accountability and clinical audit } \\
\text { Developing effective a system for clinical risk management } \\
\text { Effective implementation of family medicine } \\
\text { Health sector reform and effective implementation of new health insurance law } \\
\text { Effective application of decentralization in taking and implementing decisions } \\
\text { Developing } 2030 \text { vision and all stakeholders and community should participate in } \\
\text { preparation } \\
\text { Integration of all health care services }\end{array}$ & & \\
\hline
\end{tabular}

* Percentage exceeded the $100 \%$ due to more than one choice

Table (4) showed health experts' suggestions for improving primary health care quality were improving health budget (38.5\%), continuous evaluation, develop a system for continuous accountability and clinical audit and clinical risk management (15.4\% for each), effective implementation of family medicine, new health insurance law, decentralization in taking and implementing decisions, developing 2030 vision and all stakeholders and community should participate in its preparation and integration of all health care services ( $7.7 \%$ for each).

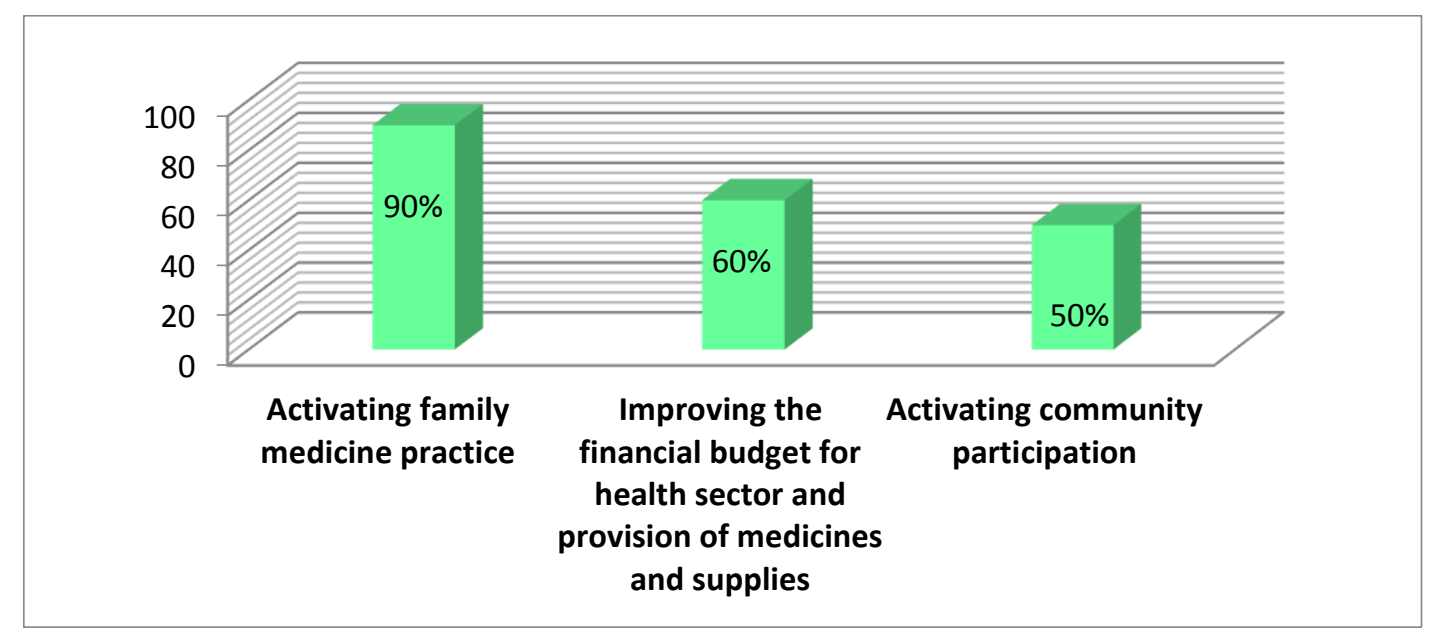

* Percentage exceeded the $100 \%$ due to more than one choice

Figure (6): Suggestions of health district directors for improving the primary health/family health care services 
Figure (6) illustrated that suggestions of health district directors for improving the primary health/ family health care services were mainly activating family medicine practice $(90.0 \%)$, then improving the financial budget to the health sector for provision of medicines and supplies (60.0\%) and activating community participation (50.0\%).

Table (5): Suggestions of health care providers for the improvement of the primary health/family health care services.

\begin{tabular}{||l|c||}
\hline \multicolumn{1}{|c|}{ Items } & Total NO.=40 \\
\hline Suggestions for improving the quality of primary health care & \\
Improving the financial budget to the health sector for provision of medicines and supplies & $36(90.0 \%)$ \\
Involving the health team in needs' identification for health facility and the community & $4(10.0 \%)$ \\
\hline
\end{tabular}

Table (5): showed that health care providers suggested mainly improving the financial budget to the health sector for provision of medicines and supplies $(90.0 \%)$ and involving the health team in identification the needs of work and the community (10.0\%) for the improvement of the primary health/family health care services

Table (6): Suggestions for improving family health services from the utilizers' view

\begin{tabular}{|c|c|c|c|c|}
\hline Studied group & $\begin{array}{l}\text { Total } \\
\mathrm{N}=327 \\
\mathbf{1 0 0 \%}\end{array}$ & $\begin{array}{c}\text { Accredited } \\
\mathbf{N}=\mathbf{2 4 9} \\
(\mathbf{7 6 . 1 \% )} \\
\end{array}$ & $\begin{array}{c}\text { Not accredited } \\
\mathrm{N}=\mathbf{7 8} \\
(\mathbf{2 3 . 9 \% )} \\
\end{array}$ & $\begin{array}{c}P- \\
\text { value }\end{array}$ \\
\hline $\begin{array}{l}\text { Suggestions } \\
\text { - Improving the budget for health for provision of } \\
\text { medicines and supplies. } \\
\text { - Availability of specialist in internal medicine, pediatrics } \\
\text { and gynecology at least one day per week for each } \\
\text { specialty. } \\
\text { - Strict oversight on health facilities. } \\
\text { - Activating community participation. } \\
\text { - Adequate and periodic training for the services } \\
\text { providers. } \\
\text { - Distribution of medicine to those who deserve and in a } \\
\text { fair manner. } \\
\text { - Reestablishment of integrated hospitals. }\end{array}$ & $\begin{array}{r}216(66.2 \% \\
54(16.5 \% \\
46(14.1 \% \\
22(6.7 \% \\
13(3.9 \% \\
4(1.2 \%) \\
2(0.6 \%)\end{array}$ & $\begin{array}{c}159(63.8 \% \\
41(16.5 \%) \\
35(14.1 \%) \\
22(8.8 \%) \\
7(2.8 \%) \\
4(1.6 \%) \\
2(0.8 \%)\end{array}$ & $\begin{array}{c}57(73.1 \%) \\
13(16.7 \%) \\
11(14.1 \%) \\
0(0.0 \%) \\
6(7.7 \%) \\
0(0.0 \%) \\
0(0.0 \%)\end{array}$ & $0.00 *$ \\
\hline
\end{tabular}

$* \mathrm{P} \leq 0.05$ is statistically significant

Table (6) showed that the utilizers reported mainly improving the budget for health for provision of medicines and supplies (66.2\%), then availability of specialist in internal medicine, pediatrics and gynecology at least one day per week for each specialty (16.5\%), strict oversight on health facilities (14.1\%), activating community participation $(6.7 \%)$, adequate and periodic training for the services providers $(3.9 \%)$, distribution of medicine to those who deserve and in a fair manner (1.2\%), reestablishment of integrated hospitals $(0.6 \%)$ as suggestions for improving family health services.

\section{DISCUSSION}

Clinical governance in primary care is viewed predominantly as a positive and welcome process, but it remains under-resourced and a challenge to implement. A cross sectional study was adopted to achieve the objectives of the study.
Efficiency is defined as provision of the service at the lowest cost and in the least time and according to quality standards ${ }^{(15)}$. The current study revealed some disparity in efficiency score, as it was the highest (91.8\%) from perspective views of directors versus utilizers $(85.0 \%)$ and providers' and experts' score ( $62.7 \% \& 58.3 \%$ respectively).

Grigoli and Kapsoli ${ }^{(16)}$ study clarified a wide spread inefficiency across health facilities in developing countries and added that reduced wastes in the use of already limited resources will improve efficiency. Novignon and Nonvignon ${ }^{(17)}$ recorded average efficiency estimates across health centers in Ghana. The average efficiency estimate was 0.51 and the average wastage was about 0.49 . They concluded that, the findings of their study suggest that there was potential for additional fiscal space to be created through improved efficiency. 


\section{ejhm.journals.ekb.eg}

Concerning clinical effectiveness, the NHS defined it as the clinical intervention which leads to the best impact on people's health within resources. People's satisfaction with the services reflects effectiveness of services provided ${ }^{(18)}$.

The current research revealed that the mean percentage score of effectiveness indicator was higher among the directors $(89.3 \%)$ than among the experts and providers $(58.3 \%$ \& $57.5 \%$ respectively). Whereas, the highest mean percentage score of effectiveness indicator (94.6\%) was from utilizers' view PHC facilities either accredited or not. These findings were similar to that recorded by El-Gammal ${ }^{(15)}$ study.

Evidence-based health is rooted in clinical practice with the emphasis on equipping clinicians with the skills needed to utilize research findings ${ }^{(19)}$. Regarding evidence-based care, there was wide discrepancy in the current study among the studied groups for the availability of scientific evidence of PHC practices as scored the highest by directors $(94.0 \%)$, less by experts $(61.5 \%)$ and the least $(15.5 \%)$ by the providers where experts and providers reported shortage in conduction of research by Ministry of Health and Populationto update the available evidence for improving the quality of PHC.

These findings were supported by several studies who mentioned that evidence-based practice poses several obstacles: the time needed to find and evaluate relevant evidence, the lack of relevance of evidence to some types of clinical problems, and information overload ${ }^{(20,21)}$.

Also, research must be conducted into areas that would meet the needs of the health care facility, and cover shortages and they added that to ensure correct establishment and implementation of scientific evidence, guidelines, protocols, and standards of services; they must be available and should be posted in places easily visible by staff, so that work can be performed according to them ${ }^{(22)}$.

Concerning training of health team, the present study reported wide variability in this indicator, where all the directors $(100 \%)$ recorded the availability of training in general, followed by experts $(67.5 \%)$ then the providers $(49.2 \%)$. The degree of efficient training is questionable.

These findings were supported by study of McSherry and Pearce ${ }^{(23)}$ who stated that for successful implementation of clinical governance, the training goals must be based on the organization's training requirements, the community it covers, and its personnel and practical experiences must be used in its planning. Also, different studies have documented inadequate health-care provider performance in low-income and middle-income countries. Therefore, they needs to be trained adequately continue to undertake ongoing education and strive for constant improvements in care and personal skill sets ${ }^{(24)}$. Measuring the practice through Clinical Audit (CA) provides the best available tool to know when change is needed ${ }^{(25)}$. In the current study, there was lack of clinical audit from view of both providers and experts $(62.5 \% \quad \& 59.0 \%$ respectively) compared to directors $(91.1 \%)$.

A study by Ivers et al. ${ }^{(26)}$ evaluated 118 clinical trials to assess the effects of audit and feedback on healthcare professionals' practice, and patients' outcomes. They concluded that their effects on the improvement of professional practice are generally modest to moderate. Effective supervision is crucial to enhancing patient safety and promoting development and maintenance of clinical competence. Indeed, $\mathrm{PHC} /$ family health teams are more in need for such supervision and direction to practical care as most of them are fresh graduates served in these health care facilities $^{(34)}$.

The goal of clinical governance is congruent with the goal of risk management, which refers to effective, efficient health care and patient safety. Health facilities require risk management to reduce inefficiency, to improve cost effectiveness, and to consider patient safety ${ }^{(27)}$.

In the current study, it was noticed that the clinical risk management indicator was scored higher score percentage than the audit from the perspective view of directors, utilizers, providers and the experts $(100 \%, 99.5 \% \& 93.3 \% 68.4 \%$ respectively). The high clinical management of risk's score may be due to limitation of the required clinical practices from PHC team, availability of referred when needed and to application of infection control program with guidelines on PHC level. In agreement, Hooshmand et al. ${ }^{(22)}$, revealed that a system of risk reporting in hospital wards, and a system of learning from mistakes is vital in risk management, which should lead to reduced incidence of mistakes.

In the present research, the majority of the interviewed providers and directors confirmed presence of policies that ensure the equitable access of PHC services to all people in different localities with equitable cost. The mean score percentage of practicing equity was approximate among the providers and directors $(58.6 \% \quad \& 62.2 \%)$ respectively while it was high among the utilizers (93.0\%). This discrepancy in equity score may come from differences in questions for both questionnaires, as the utilizers were asked only about to what extent they feel equal when they are getting the service while the directors and providers were asked about equality in salaries and fairness in appointment in their jobs beside equity in provision of health services. On the contrary, a study mentioned that the higher household income group was more likely to experience better $\mathrm{PHC}^{(27)}$. Also, El-Gammal ${ }^{(15)}$ reported lower equity indicator score (73.8 degree) in the government sector than in the private sector ( 94.4 degree). People mentioned feeling unequal in getting the PHC services was due to: prevalence of bribes and 
"wasta", which shows the correlation between equity and absence of corruption.

Concerning transparency, it can serve to limit or prevent many of opportunities for corrupt behaviors. The present study, revealed low transparency mean percentage score among health care providers $(33.8 \%)$ versus directors $(81.0 \%)$. From the utilizers' perspectives, the mean percentage of transparency indicator was $(61.5 \%)$. While, among experts there was a gap between health information management indicator mean percentage score $(61.5 \%)$ and transparency indicator (20.5\%). On the contrary, El-Gammal ${ }^{(15)}$ demonstrated that transparency indicator got low degree of score in private PHC sector than the governmental one (15.2 degree versus 15.9 degree respectively) at Fayoum governorate.

In the present study, lack of participation was the next obstacle where the mean percentage of this indicator was $(0.2 \%)$ among PHC utilizers. This indicated that there was very low community participation in all items representing the participation activities however, health care directors viewed there is participation of citizens and health care team with very high score percentage (96.7\%) while, for the experts and providers ' views were low $(36.5 \% \quad \& 55.8 \%$ respectively).

In agreement, El-Gammal ${ }^{(15)}$ reported low participation indicator in PHC (0.8 out of 100). They clarified that the lack of transparency and low rate of information dissemination eventually caused weak citizen's participation in evaluating the quality of the services, or in needs assessment. Naturally, people do not participate in what they do not know. They added that the health services are very specialized and complicated, which do not give a space for ordinary people to participate. It seems to need clear and effective mechanisms to engage civil society.

In consistency, barrier impeding active participation of hospital staff in the CG promotion to lack of incentives ${ }^{(28)}$.

Regarding responsiveness indicator, findings of the present study clarified low mean percentage score (50.5\%) among the PHC utilizerswith wide variability between providers and directors $(69.6 \% \quad \& 100 \%$ respectively). These findings were similar to ElGammal $^{(\mathbf{1 5})}$ as the index showed (51.9 degree of 100) response for the government sector to people's needs compared to the private sector (80.8 degree out of 100). A responsive system is one that gives the patient a choice of services, and provides the service appropriate for the patient's disease in shortest possible time ${ }^{(29)}$.

In the present study, PHC utilizers recorded the lowest accountability indicator (13.4\%). Whereas high among experts, providers and directors $(59.0 \%, 65.3 \%$, $95.8 \%$ respectively). These findings were to some extent similar to El-Gammal ${ }^{(\mathbf{1 5})}$ as accountability index scored low degrees in both sectors delivering the PHC (22.8 degrees in government sector and 17.6 degrees in private sector out of 100) and the degree of filing complaints was less than one. They do not know how to file them and where to go. They also respond that "nothing will change". Cultural changes is required to be more community active, responsive and insist to attain its rights ${ }^{(30)}$.

In agreement, study by Kaini ${ }^{(31)}$ recorded that the lack of accountability in the health services is one of the contributory factors for failure of effective and efficient health services in Nepal. He emphasized that accountability is the basic ingredient of professional code of conduct and a fundamental aspect of professionalism of healthcare professionals.

Corruption is any abuse of power or privileges for personal gains in the course of rendering medical services ${ }^{(32)}$. In the present study, the mean percentage score of combating corruption among the PHC utilizers was low (54.6\%) compared to that among providers and directors $(66.8 \% \& 72.5 \%$ respectively).

These findings were to some extent similar to study of El-Gammal ${ }^{(\mathbf{1 5})}$ as combating corruption indicator score was (74.8 degree). They reported that citizens' perception on prevalence of corruption in government $\mathrm{PHC}$ is higher than that in the private sector. However, the exposure to acts of corruption is low (7.4 degrees in the government sector, and 3 degrees in the private sector). Moreover, the reporting of the acts of corruption came very low (only one respondent out of those exposed to an act of corruption in the government sector and two respondents in the private sector).

Research by Matsheza et al..$^{(33)}$ clarified that the factors that drive corruption in the health sector are due to weak or absent of rules and regulations, lack of accountability, low salaries, inadequate services and absenteeism. In addition, health professionals are hardly accountable to regulatory bodies and the execution of standards sometimes inadequate or absent due to low financial and human resources.

In the present study, weak enforcement of the role of law is another barrier detected and demonstrated by wide variability in its mean percentage $(40.2 \%$, $48.7 \%$ \& $100 \%$ ) among providers, experts and directors respectively. Without regulations or adoptions of role of laws, doors will be opened for corruption especially with absence of transparency\& accountability.

Concerning $C G$ index, the current study denotedthat PHC directors scored higher percentage degree by $(91.0 \%)$ than by PHC utilizers, providers and the experts $(70.0 \%, 59.6 \% \& 53.3 \%$ respectively) as the executive directors yield the highest scores in all CG elements versus experts.

This could be explained that the experts may saw the general CG situation on the national level which 
may be right; however the executive directors saw the local situation which may also right for one of the best health indicators governorate.

The present study revealed that the majority (84.6\%) attributed the challenges in CG implementation will belack activation of the policies due to unstable political environment, lack of awareness about governance culture and lack of experience in this field. Also, they added that absence of real will to implement its aspects, fragmentation of services provision and inappropriate organizational structure of health system, absence of participatory vision and action between all stakeholders, weak supervision and monitoring as well as inappropriate health care work environment. These are the same challenges reported by several studies in this issue ${ }^{(34)}$.

\section{REFERENCES}

1. Scally G, Donaldson L (1998): Clinical governance and the drive for quality improvement in the New NHS in England. Br Med J., 317(7150):61-65.

2. Haxby E, David HH, Jaggar S (2010): An Introduction to Clinical Governanceand Patient Safety. 1st ed., New York: Oxford University Press.

3. Dickinson A (2009): Clinical Governance Strategy 20092012. Available on: http://www.leeds.nhs.uk .

4. BinagwahoA, Ghebreyesus TA (2019): Primary healthcare is cornerstone of universal health coverage. BMJ., 365:12391-19395.

5. World Health Organization and the United Nations Children's Fund (2018): A vision for primary health care in the 21st century: towards universal health coverage and the Sustainable Development Goals. https://www.who.int/docs/default-source/primary-healthcare-conference/phc-regional-report-easternmediterranean.pdf?sfvrsn=2a5a2528_2

6. Hall JJ, Taylor R (2003): the demise of the Alma-Ata Declaration and primary health care in developing countries. Medical Journal of Australia, 178(1):17-20.

7. Walley J, Lawn JE, Tinker A et al. (2008): Primary health care: making Alma-Ata a reality. The Lancet, 372(9642): 1001-1007.

8. CAPMAS (2016): Government of Egypt, statistical year book. Available from: http://www.capmas.gov.eg/ Pages/StaticPages.aspx

9. El-Zanaty F (2014): Egypt Demographic and Health Survey 2014. Available from: http://dhsprogram.com/pubs/pdf/PR54/PR54.pdf

10. WHO (2004): Quality improvement in primary health care: a guide.https://apps.who.int/iris/handle/10665/119694

11. WHO (2007): Everybody's business--strengthening health systems to improve health outcomes: WHO's framework for action. Available on: https://apps.who.int/iris/handle/10665/43918

12. Hamza M (2017): Egypt's Universal Healthcare ActEnterprise Press. enterprise.press/wpcontent/.../2017/12/Egypts-Universal-Healthcare-Act-APrimer.pd
13. El-Megharbel N (2015): sustainable Development Strategy:Egypt's vision 2030and Planning Reform. https://sustainabledevelopment. un.org/content/documents/ $15262 \mathrm{El}-$ Megharbell,\%20Egypt\%20NSDS\%2020150527.pdf

14. Mostafa S, El-Shourbagy O (2012): Omar's Applied And Medical Statistics. Egyptian National Library Catalog No.2002-14314; (5 ${ }^{\text {th }}$ Edition), p49-151.

15. El-Gammal M (2014): Towards Good Governance in Primary Health Care Services (Case Study: Fayoum Governorate). Social Contract Center. https://www.redalyc.org/html/2750/275019712005/

16. Grigoli F,Kapsoli J (2018): Waste not, want not: The efficiency of health expenditure in emerging and developing economies. Review of Development Economics, 22(1): 384-403.

17. Novignon J, Nonvignon J (2017): Improving primary health care facility performance in Ghana: efficiency analysis and fiscal space implications. BMC Health Services Research, 17(1): 399-405.

18. McClareM (1997): 'Clinical Effectiveness and EvidenceBased Practice', Nursing Standard, 11(52): 33-7.

19. Rosenberg $\mathbf{R}$ (2003): Translating biomedical research to the bedside: a national crisis and a call to action. Journal of the American Medical Association, 289:1305-6.

20. Young J, Ward J (2001): Evidence-based medicine in general practice: beliefs and barriers among Australian GPs. Journal of Evaluation in Clinical Practice, 7:201-10.

21. Ely JW, Osheroff JA, Ebell MH et al. (2002): Obstacles tocanswering doctors' questions about patient care withcevidence: qualitative study. British Medical Journal, 324:710-13.

22. Hooshmand E, Tourani S, Ravaghi H et al. (2014): Challenges in evaluating clinical governance systems in Iran: a qualitative study. Iranian Red Crescent Medical Journal,16(4): e13421.

23. McSherry R, Pearce P (2011): Clinical Governance: A Guide to Implementation for Healthcare Professionals. 3rd edition.Chichester: Wiley-Blackwell.

24. Hogerzeil HV, Liberman J, Wirtz VJ et al. (2013): Promotion of access to essential medicines for noncommunicable diseases: practical implications of the UN political declaration.Lancet, 381: 680-689.

25. Benjamin A (2008): Audit: how to do it in practice. BMJ., 336:1241-5.

26. Ivers N, Jamtvedt G, Flottorp S et al. (2012): Audit and feedback: effects on professional practice and healthcare outcomes. https://www.cochrane.org/.../EPOC_auditand-feedback-effects-on-professional-practi..

27. South Australian health(2018). Clinical governance framework for Allied Health professionals. http://www.health.sa.gov.au/alliedandscientifichealth

28. Sidin AI, Pasinringi SA (2014): A Critical Review of The Role of Clinical Governance in Health Care and its Potential Application in Indonesia. The International Journal of Business Management, 2(7):74-82.

29. Adagbabiri MM (2015): Accountability and transparency: an ideal configuration for good governance..https://www.iiste.org/Journals/index.php/D CS/article/viewFile/27454/28168

30. Dehnavieh R, Ebrahimipour $\mathrm{H}$, Zadeh $\mathrm{MJ}$ et al. (2013).Clinical Governance: The Challenges of 
ejhm.journals.ekb.eg

Implementation in Iran. International Journal of Hospital Research, 2(1):1-10.

31. Kaini BK (2013): Healthcare governance for accountability and transparency.J Nepal Health Res Counc., 11(23):109-11.

32. Tormusa DO,Idom AM (2016): The impediments of corruption on the efficiency of healthcare service delivery in Nigeria. Online Journal of Health Ethics, 12(1): 3-7.

33. Matsheza H, Timilsina AR,Arutyunova A (2011):Fighting corruption in the health sector methods, tools and good practices. http://www.undp.org/content/undp/en/home/librarypage/ democratic-governance/anti-

corruption/fighting_corruptioninthehealthsector.html.

34. Campbell SM, Sheaff R, Sibbald B et al. (2002): Implementing clinical governance in English primary care groups/trusts: reconciling quality improvement and quality

assurance.https://qualitysafety.bmj.com/content/11/1/9

35. Ferdosi M, Ziyari $\mathrm{F}$, Ollahi MN et al. (2016):Implementing clinical governance in Isfahan hospitals: Barriers and solutions, 2014.Journal of Education and Health Promotion, 5:20-28. 